\title{
Práticas educativas CTS: busca de uma participação social para além da avaliação de impactos da Ciência-Tecnologia na Sociedade
}

\author{
STS educational practices: the search for social participation \\ beyond the assessment of impacts of Science-Technology \\ on Society
}

\author{
Rosemar Ayres dos Santos ${ }^{1}$ \\ https://orcid.org/0000-0002-1068-2872 \\ Décio Auler ${ }^{2}$ \\ https://orcid.org/0000-0001-8802-1428
}

\begin{abstract}
Resumo: A problematização da suposta neutralidade da Ciência-Tecnologia para a constituição de uma cultura de participação em processos decisórios é fundamental. Investigamos quais os encaminhamentos em práticas educativas Ciência-Tecnologia-Sociedade, no contexto brasileiro, contemplam a presença de valores, de interesses no direcionamento dado ao desenvolvimento científico-tecnológico. $\mathrm{Na}$ análise do corpus, composto por artigos de edições do Encontro Nacional de Pesquisa em Educação em Ciências (ENPEC), e de periódicos, utilizamos a Análise Textual Discursiva. Sintetizamos os resultados em: (i) superação do determinismo científico-tecnológico; (ii) valores e características de determinado espaço-tempo condicionam a agenda de pesquisa, o produto científico-tecnológico; (iii) participação social na definição da agenda de pesquisa em Ciência-Tecnologia; (iv) encaminhamentos promissores; (v) participação social limitada às implicações/impactos da Ciência-Tecnologia na Sociedade. Sinalizamos a necessidade de assumir novo objetivo em processos educativos: potencializar para a participação em processos decisórios envolvendo a formulação de políticas públicas para a Ciência-Tecnologia.
\end{abstract}

Palavras-chave: Ciência, tecnologia e sociedade. Participação social. Neutralidade científica.

\begin{abstract}
It is crucial to problematize the supposed neutrality of Science-Technology for the constitution of a culture of participation in decision-making processes. We have investigated which procedures have been deployed in Science-Technology-Society educational practices, in the Brazilian context, which take into account values and interests in how scientific-technological development is promoted. The analysis of the corpus was composed of papers from different editions of Encontro Nacional de Pesquisa em Educação em Ciências (ENPEC) and journal articles, Discursive Textual Analysis has been used. The findings can be summarized as follows: (i) shifts that go beyond scientific-technological determinism; (ii) values and characteristics of given space-time influence the research agenda, the scientific-technological product; (iii) social participation in setting the research agenda in Science-Technology; (iv) promising routes; (v) social participation limited to the implications/impacts of Science-Technology for/on Society. We point to the need to define new objectives in educational processes: leverage for participation in decision-making processes involving the formulation of Public Policies for ScienceTechnology.
\end{abstract}

Keywords: Science, technology and society. Social participation. Scientific neutrality.

\footnotetext{
${ }^{1}$ Universidade Federal da Fronteira Sul (UFFS), Programa de Pós-Graduação em Ensino de Ciências, Cerro Largo, RS, Brasil. E-mail: rosemar.santos@uffs.edu.br

${ }^{2}$ Universidade Federal de Santa Maria (UFSM), Programa de Pós-Graduação em Educação, Santa Maria, RS, Brasil.
} 


\section{Situando o problema de pesquisa}

Entendemos que, muitas vezes, particularmente no campo Ciência-TecnologiaSociedade (CTS), postula-se uma participação social muito limitada em processos decisórios envolvendo Ciência-Tecnologia (CT). Limitada porque se reduz a uma avaliação dos impactos de produtos científico-tecnológicos na sociedade. Não se problematiza o fato de que a não neutralidade da CT tem sua gênese na definição da agenda de pesquisa, no direcionamento dado ao desenvolvimento científico-tecnológico, dimensões condicionadas por valores. Assim, não sendo um processo neutro, consideramos ser um direito da sociedade como um todo participar.

Nesse sentido, para potencializar essa participação, compreendemos como necessária a problematização da suposta neutralidade da CT, entendendo que essa compreensão sustenta e legitima modelos decisórios tecnocráticos, podendo fragilizar a constituição de uma efetiva cultura de participação.

Em pesquisas anteriores há sinalizações para a necessidade de ampliar a compreensão sobre a não neutralidade da CT. Por exemplo, Auler (2002), Auler e Delizoicov (2015), Delizoicov e Auler (2011), Rosa (2014), e Santos (2012), assim como no denominado Pensamento Latino-Americano em CTS (PLACTS). Contudo, em pesquisa tendo como corpus literatura do campo CTS brasileiro, Rosa (2014) concluiu que, majoritariamente, ignora-se o campo axiológico. Em outros termos, subestima-se o papel dos valores no direcionamento dado ao desenvolvimento científico-tecnológico. Vinculado a isso, no campo educacional, nos encaminhamentos CTS, em geral, a defesa de participação da sociedade, em processos decisórios, limita-se à pós-produção, à pós-definição da agenda de pesquisa, dos rumos desse desenvolvimento. Entendemos que tal participação é muito limitada, ocorrendo após a definição do essencial.

A expressão Pensamento Latino-Americano em Ciência-Tecnologia-Sociedade (PLACTS) foi sugerida por Dagnino (2008a), referindo-se ao conjunto das contribuições de cientistas latino-americanos, em especial dos argentinos Herrera (1971, 1973), Sábato e Mackenzie (1982), e Varsavsky $(1969,1976)$. Seus trabalhos foram desenvolvidos na década de 1960 em países da América Latina, principalmente na Argentina. Esse pensamento, em linhas gerais, questiona a transferência tanto tecnológica (intensificada naquele momento histórico), quanto das Políticas Científico-Tecnológicas (PCT) do Hemisfério Norte para a América Latina.

Assim, já na década de 1960, esses autores destacavam que, na transferência tecnológica, o que se transfere não são apenas instrumentos neutros, utilizáveis para o bem ou para o mal, como faz crer um discurso, transformado em senso comum, ainda fortemente presente, também, na academia. Tais instrumentos, ou produtos científico-tecnológicos, materializam, carregam valores, interesses presentes na origem, nos contextos em que foram concebidos. Ainda propunham superar a transformação da agenda de pesquisa latino-americana numa mera estação retransmissora do que ocorria no Hemisfério Norte. Dagnino (2008a) destaca que o campo macroeconômico, aspectos históricos, assim como a imposição e/ou submissão econômica e cultural, configuravam e continuam configurando, nessa região, uma PCT que é disfuncional para a solução dos problemas do conjunto da sociedade. Ainda segundo Dagnino (2008a), contrariamente ao que ocorreu com o movimento CTS, no Hemisfério Norte, o PLACTS não teve, naquele momento histórico, repercussões no campo educacional. 
O discurso de que a tecnologia não é nem boa e nem ruim, de que tudo depende do uso ${ }^{3}$ que dermos a ela, é a forma mais acabada de neutralidade. Esse discurso ignora, por exemplo, que aspectos indesejáveis vinculados à tecnologia não decorrem apenas de um suposto mau uso. A ocorrência desses é previsível. Representa uma decorrência dos interesses, das características, dos valores que, materializados no produto científico-tecnológico, assumem determinadas características que se manifestam independente de um suposto bom ou mau uso (AULER, 2002). Por exemplo, a degradação socioambiental contemporânea não decorre apenas de um mau uso dos atuais produtos científico-tecnológicos, mas, acima de tudo, porque o direcionamento dado a esse desenvolvimento está alinhado a valores consumistas: a obsolescência programada, a descartabilidade.

Entretanto, nossa compreensão não defende que todas as tecnologias estão marcadas pelo mal, recaindo em um novo maniqueísmo, mas que há a necessidade de um reprojetamento, segundo outros valores, da CT atual, o que Dagnino (2010) denomina de Adequação Sociotécnica (AST). Reprojetamento associado à busca de um projeto alternativo de sociedade, de uma nova Política Científico-Tecnológica (PCT), definida com uma crescente participação da sociedade, discutindo-se possíveis configurações sociais associadas à adoção dessa ou daquela CT. Essa compreensão não exclui, ainda, a dimensão da apropriação mais igualitária de produtos científico-tecnológicos existentes.

Entendemos como fundamental a problematização dessas questões no contexto educacional. Problematização possibilitada por aproximação construída entre o educador brasileiro Paulo Freire e encaminhamentos do campo CTS. Aproximação analisada, dentre outros autores, em Auler (2002, 2007), Monteiro, Gouvêa e Sánchez (2010), Nascimento e Linsingen (2006), Rosa, Roso e Santos (2012), Roso, Dalmolin e Auler (2011), W. L. P. Santos (2008), e Santos et al. (2010). Auler (2007) sintetiza possibilidades de aproximação em três eixos: (i) currículo estruturado em torno de temas/problemas reais; (ii) dimensão interdisciplinar no enfrentamento desses temas / problemas; (iii) busca da democratização de processos decisórios. Contudo, tanto como movimento social mais amplo, quanto nas repercussões educacionais, CTS é bastante polissêmico. Segundo Auler (2007), há encaminhamentos, no campo CTS, incompatíveis com a perspectiva crítica e transformadora de Paulo Freire.

Considerando possíveis complementariedades entre Freire-CTS, se Freire contribui com objetivos educacionais - dimensão pobre no campo CTS (STRIEDER, 2012) - sua postulação de uma leitura crítica da realidade pode ser potencializada com uma compreensão crítica das interações entre Ciência-Tecnologia-Sociedade, algo fundamental na dinâmica social contemporânea, não aprofundado por Paulo Freire. Os autores que trabalham com a aproximação desses referenciais consideram relevante a problematização da suposta neutralidade da

\footnotetext{
${ }^{3}$ A tecnologia (gene) terminator ajuda na problematização dessa compreensão. Um gene que, como o próprio nome diz, é exterminador. Quando incorporado às sementes transgênicas, torna-as estéreis, ou seja, as sementes geradas pela planta não irão nascer. Uma intencionalidade que subjuga os agricultores a poucas empresas vendedoras de sementes. Qual o sentido, qual a relevância social na socialização dessa tecnologia? Cabe a lógica do bom ou mau uso? Haveria um bom uso para essa tecnologia, se a essência da semente foi excluída: germinar e produzir novas plantas. Não é possível dar um bom uso para aquilo que está marcado pela morte, não pela possibilidade de geração da vida.
} 
CT, aspecto parcialmente presente no campo CTS. Presença apenas parcial, considerando que muitos desses encaminhamentos ignoram, não abordam, o papel dos valores no direcionamento dado ao desenvolvimento científico-tecnológico.

Se essa dimensão (direcionamento) esteve presente no surgimento do movimento CTS como movimento social mais amplo (GARCÍA; CEREZO; LÓPEZ, 1996), há indicativos de que, em sua repercussão, no campo educacional, tenha sido bastante ignorada. São incipientes as pesquisas e práticas curriculares que, efetivamente, trabalham, que problematizam a questão da não neutralidade da CT em toda sua amplitude. Essa constitui preocupação que culmina com a formulação do problema de pesquisa que resultou no trabalho aqui apresentado: Quais encaminhamentos têm sido dados, em práticas educativas Ciência-TecnologiaSociedade, no contexto brasileiro, que contemplam a presença de valores, de interesses no direcionamento dado ao desenvolvimento científico-tecnológico?

\section{Encaminhamentos Teórico-Metodológicos}

Este artigo constitui síntese de pesquisa mais ampla (SANTOS, 2016), a qual se configurou como uma pesquisa qualitativa de cunho documental (GIL, 2008). Essa teve como objetivos: (1) aprofundar conceitualmente a compreensão de que valores que definem o direcionamento dado ao desenvolvimento da CT, são internalizados e materializados no produto científico-tecnológico; (2) identificar práticas educativas que trabalham a presença de valores no direcionamento dado ao desenvolvimento científico-tecnológico; (3) analisar e socializar práticas educativas que trabalham a presença de valores no direcionamento dado ao desenvolvimento da CT.

Práticas educativas, aqui, compreendidas segundo a perspectiva freireana (FREIRE, 2005) de práxis. Uma articulação, um diálogo entre teoria e prática. Ou seja, o segundo critério de seleção, na constituição do corpus de análise, em seguida explicitado, buscou selecionar artigos que, além de vinculados ao campo CTS, deveriam ter como foco alguma intervenção curricular efetivada em processos educativos. Considerando tratar-se de um foco de pesquisa incipiente, qual seja a presença de valores no direcionamento da atividade científico-tecnológica, optamos por um estudo em extensão. Aspecto que demanda aprofundamentos em pesquisas futuras. Aprofundamentos que poderão revelar sinalizações promissoras, assim como fragilidades decorrentes da falta de contato com as práticas educativas originais analisadas nos artigos do corpus.

Esse corpus de análise foi composto por artigos presentes nas atas das nove primeiras edições do Encontro Nacional de Pesquisa em Educação em Ciências (ENPEC), no período compreendido entre 1997 e 2013, e artigos de quatro periódicos da área de Educação em Ciências (EC): Alexandria: Revista de Educação em Ciência e Tecnologia, Ciência \& Educação, Ensaio: Pesquisa em Educação em Ciências e Revista Brasileira de Pesquisa em Educação em Ciências (RBPEC). A opção por essas fontes considera que as mesmas possuem representatividade, em nível nacional, constituindo o principal espaço de divulgação e de discussão das pesquisas realizadas no âmbito da EC. O período de abrangência focalizou a data da criação do periódico até a última edição de 2014. Como primeiro critério de seleção, os artigos deveriam conter no título, no resumo ou nas palavras-chaves todas as formas de manifestação das palavras CTS e/ ou CTSA. Com esse critério, selecionamos 204 artigos do ENPEC e 56 dos periódicos. 
A partir desse conjunto, utilizamos um segundo critério. Os artigos deveriam ter como foco de análise práticas educativas efetivamente realizadas e/ou implementadas. Assim, o total final de artigos selecionados foi de 93 (ENPEC, 74 e periódicos, 19). Os artigos identificados como AE01 a AE74 foram obtidos do ENPEC. AP01 a AP19 foram extraídos dos periódicos. Artigos com excertos citados no presente trabalho estão sintetizados no quadro 1, com os dados completos na lista de referências.

Quadro 1 - artigos pesquisados citados no presente trabalho

\begin{tabular}{|l|l|}
\hline Identificação & \multicolumn{1}{|c|}{ Citação autor-ano } \\
\hline AE03 & MION; ANGOTTI; BASTOS, 1999 \\
\hline AE09 & ALVES; CARVALHO, 2005 \\
\hline AE11 & CARLETTO; PINHEIRO, 2005 \\
\hline AE17 & SOUSA et al., 2005 \\
\hline AE23 & FIRME; AMARAL, 2007 \\
\hline AE25 & MEZALIRA; ARAÚJO, 2007 \\
\hline AE29 & SOUSA; ALENCAR, 2007 \\
\hline AE37 & ABREU; LIMA; MARTINS, 2011 \\
\hline AE50 & MIRANDA et al., 2011 \\
\hline AE51 & NIEZER; SILVEIRA; SAUER, 2011 \\
\hline AE56 & SANTOS; FERRARI; ALMEIDA, 2011 \\
\hline AE58 & SILVA; PESSANHA; BOUHID, 2011 \\
\hline AE68 & PANIAGUA; SILVAS; MACHADO, 2013 \\
\hline AE69 & PORTO; TEIXEIRA, 2013 \\
\hline AP01 & ARAÚJO; FORMENTON, 2012 \\
\hline AP05 & ANDRADE; CARVALHO, 2002 \\
\hline AP17 & BARBOSA; BAZZO, 2013 \\
\hline
\end{tabular}

Fonte: elaborado pelos autores.

Para a análise desse corpus, apropriamo-nos da Análise Textual Discursiva (ATD) (MORAES, 2003; MORAES; GALIAZZI, 2013), na qual, a partir desse conjunto de textos (artigos), produzimos um novo texto. A ATD é constituída de três etapas: a unitarização - os textos "[...] são separados em unidades de significado. Essas unidades por si mesmas podem gerar outros conjuntos de unidades oriundas da interlocução empírica, da interlocução teórica e das interpretações feitas pelo pesquisador" (MORAES; GALIAZZI, 2006, p. 118); a categorização - são agrupados elementos com significados semelhantes, compondo as categorias, e a comunicação - são produzidos os metatextos analíticos a partir das categorias e subcategorias resultantes da análise. Esses metatextos são compostos de descrição e interpretação, que representam a compreensão e a teorização alcançadas sobre os fenômenos investigados. 
A seleção e análise do corpus foi guiada por duas dimensões: o problema e os objetivos da pesquisa, citados anteriormente, assim como o referencial teórico, constituído por Freire (1996, 2005, 2009), Freire e Faundez (1985), Pensamento Latino-Americano em Ciência-Tecnologia-Sociedade (DAGNINO, 2008a, 2008b, 2010, 2011), Lacey (2008, 2010) e encaminhamentos Ciência-Tecnologia-Sociedade. Freire ajuda-nos a compreender que, para a constituição de uma cultura de participação, torna-se fundamental uma leitura crítica da realidade. Leitura crítica possibilitada por uma compreensão crítica das interações entre CiênciaTecnologia-Sociedade - problematização e superação da suposta neutralidade - aspecto que encontra contribuições no campo CTS. Apoiados em Dagnino, Lacey e o PLACTS, aprofundamos a compreensão de que o direcionamento dado ao processo científico-tecnológico não é neutro, mas marcado por valores e interesses. Não sendo neutro, pelas convicções assumidas, postulamos uma participação social mais ampla. Postulação trabalhada a partir desses últimos referenciais. Da unitarização realizada, 245 núcleos de significado (excertos/unidades de sentido) foram identificados. Do processo de categorização, resultaram cinco categorias.

\section{Resultados}

Com a imersão no corpus de análise, das duas primeiras etapas da Análise Textual Discursiva, a unitarização e a categorização, resultaram as cinco categorias: (1) superação do determinismo científico-tecnológico; (2) valores e características de determinado espaço-tempo condicionam a agenda de pesquisa, o produto científico-tecnológico; (3) participação social na definição da agenda de pesquisa em Ciência-Tecnologia; (4) encaminhamentos promissores; e, (5) participação social limitada às implicações/impactos da Ciência-Tecnologia na Sociedade.

\section{Superação do determinismo científico-tecnológico}

Essa categoria sinaliza indicativos de superação do determinismo científico-tecnológico, com manifestações explícitas em $19^{4}$ núcleos de sentido (significado) de um total de 245. No conjunto, isso representa um número pequeno, resultado coerente com pesquisa realizada por Rosa (2014), com corpus de análise, em parte, distinto do atual, na qual identificou que predominavam silenciamentos sobre a concepção e produção da CT, o que poderia indicar o endosso ao determinismo científico-tecnológico. Determinismo consistindo de concepção que defende existir uma única trajetória para o desenvolvimento da $\mathrm{CT}$, sendo CT determinantes na constituição de todas as outras instituições na sociedade (DAGNINO, 2008b).

Número pequeno, mas promissor. Sinalizando superação da concepção determinista, AE29, ao discutir a implementação de uma proposta de ensino com estudantes do Ensino Médio, em duas escolas, manifesta entendimento que a CT não é neutra, carrega valores, intencionalidades, que ela influencia a sociedade, mas também é influenciada por essa sociedade. $\mathrm{Na}$ proposta constituída de júri simulado, envolvendo um aparato tecnológico, os estudantes

\footnotetext{
${ }^{4}$ Um mesmo núcleo de sentido (excerto) pode comparecer em mais de uma categoria.
} 
argumentaram “[...] 'contra' e 'a favor' do uso do motor à combustão interna. Enfatizamos as implicações sociais do dispositivo, bem como as pressões sociais e históricas que provocaram e ainda têm mantido o desenvolvimento de tecnologias relacionadas ao mesmo" (SOUSA; ALENCAR, 2007, p. 7).

Esses autores/pesquisadores argumentam, também, sobre a influência da sociedade nas definições, no direcionamento dado ao desenvolvimento da CT: "em ambos os contextos educacionais, tratamos de mostrar a ideia de uma ciência não neutra, contrariando a noção usual de imparcialidade científica, [...], que influencia e se deixa influenciar por demandas sociais e tecnológicas" (SOUSA; ALENCAR, 2007, p. 7, grifo nosso).

Entendemos que essas manifestações contêm elementos que vão além da visão tradicional de CT, contrariam um senso comum conformista que atribui à CT autonomia e neutralidade. Contribuem para problematizar a passividade social de uma não participação nas tomadas de decisão em relação aos rumos do desenvolvimento da CT. Também indicando para a superação da concepção determinista, comparece manifestação presente no artigo AE50. Aparece a ideia de mão dupla: CT determinando a vida social, mas também os formatos da vida social determinando CT. Ou seja,

[...] no decorrer da história da humanidade, a ciência e a tecnologia têm sido determinantes nos modelos da vida social. Isso implica em dizer que, do mesmo modo, historicamente os formatos da vida social são determinantes do desenvolvimento científico e tecnológico. (MIRANDA et al., 2011, p. 3, grifos nossos).

Destacamos outros núcleos de sentido apontando para a superação da concepção determinista:

Ciência e Tecnologia compreendidas como domínios distintos que se influenciam mutuamente na construção de conhecimentos, e que tanto promovem modificações nas formas de vida da sociedade, como podem ser influenciadas por esta sociedade através de políticas públicas. (FIRME; AMARAL, 2007, p. 3, grifos nossos).

Evidenciar como os contextos social, cultural e ambiental, nos quais se situam a ciência e a tecnologia, influenciam a condução e o conteúdo das mesmas; como ciência e tecnologia, por sua vez, influenciam aqueles contextos e, finalmente, como ciência e tecnologia têm efeitos recíprocos e suas inter-relações variam de época para época e de lugar para lugar [...] (BARBOSA; BAZZO, 2013, p. 154, grifos nossos).

Desse modo, sinalizações que apontam para a superação do determinismo científicotecnológico, encontradas em práticas educativas CTS, são promissoras, considerando que a superação dessa concepção está relacionada à superação de uma concepção de CT neutras. Para Auler (2002), a suposta neutralidade está estreitamente relacionada com o determinismo. Essas sinalizações promissoras remetem para o campo dos valores. Valores como dimensão 
importante no direcionamento dado ao desenvolvimento da CT. Podem constituir a gênese para uma compreensão ampliada de participação social. Ou seja, se o desenvolvimento da CT não tem vida própria, mas impulsionado por interesses e valores, estes, contemplando o conjunto da sociedade, numa educação crítica e transformadora, precisam estar representados nas PCT.

\section{Valores e características de determinado espaço-tempo condicionam a agenda de pesquisa, o produto científico-tecnológico}

Nessa categoria compareceram 50 núcleos de sentido, tendo como característica a compreensão da presença de valores, de intencionalidades presentes na definição da agenda de pesquisa, na produção de aparatos científico-tecnológicos. Há a constatação de que, no direcionamento dado à CT, das opções tecnológicas escolhidas, dos aparatos científico-tecnológicos construídos, na mudança tecnológica, comparecem valores, características presentes na sociedade. Por exemplo, “[...] tal associação com o cotidiano mostra, na realidade, que ciência e tecnologia nada mais são do que a aplicação sistemática de valores humanos que prezamos e desenvolvemos [...]” (NIEZER; SILVEIRA; SAUER, 2011, p. 4, grifo nosso). Ou “[...] busque questionamentos a respeito dos modelos e valores de desenvolvimento científico e tecnológico da atual sociedade" (PANIAGUA; SILVAS; MACHADO, 2013, p. 3).

Há um conjunto de falas nas quais é bastante marcante a influência do campo dos valores. Destacamos duas: "Para isso, é necessário que se caracterize a Ciência como uma atividade não neutra, isto é, com vinculações políticas, sociais, econômicas e culturais na sua produção [...]” (ANDRADE; CARVALHO, 2002, p. 168, grifos nossos).

\footnotetext{
Os alunos puderam refletir sobre: a Ciência e os cientistas; sobre a Tecnologia e sua relação com o estilo de vida; sobre os fatores socioeconômicos a orientar a própria evolução da Ciência-Tecnologia; como a lógica do mercado capitalista define padrões de consumo; a importância da participação individual e social na busca pelos seus direitos; a necessidade de fazer opções responsáveis e conscientes (PORTO; TEIXEIRA, 2013, p. 8).
}

Outras análises, além de enfatizar que há a presença de valores nesse direcionamento, constatam que essa Sociedade não é homogênea, havendo interesses específicos, destacando que o desenvolvimento da CT está associado a determinados projetos humanos. "[...] uma abordagem do conhecimento científico, enquanto construção humana, e por isso considerado como relativo e provisório, assim, vinculado a um contexto social, político e econômico de grupos específicos [...]” (ABREU; LIMA; MARTINS, 2011, p. 2). Ou ainda,

O entendimento do processo de construção do conhecimento científico e da natureza da ciência é importante para a compreensão de que a ciência é construída socialmente e de que vem atendendo historicamente aos interesses dos grupos que detém o poder cognitivo, econômico e político (SILVA; PESSANHA; BOUHID, 2011, p. 3).

Ter consciência da presença de valores constitui nível de compreensão mais elementar 
do que ter consciência de que há valores distintos, associados a distintas classes sociais, a distintas culturas. Apesar das falas anteriores, no conjunto dos artigos analisados, está ausente a compreensão de que o poder econômico, de grupos específicos e a submissão dos despossuídos, faz com que parcela significativa da sociedade não consiga exercitar uma plena cidadania, uma plena participação. Sua posição subalterna, na sociedade, contribui para que sejam desconsideradas suas demandas (DELIZOICOV; AULER, 2011), seus valores e necessidades na formulação de políticas públicas para CT.

O conjunto dos núcleos de sentido, que dão consistência a essa categoria, podem estar sinalizando para um cenário promissor. Começam a acontecer na sala de aula discussões sobre a presença de valores no direcionamento dado ao desenvolvimento da CT. Contudo, também podem estar sendo colocados, para processos educativos, imensos desafios. Parece estar constituindo-se a constatação de que não é um processo neutro, de que há a presença de valores. Porém, o que fazer com essa constatação? Pensamos que, se não houver a discussão, a busca de outros, de novos horizontes, há o risco de gerar imobilismo: tudo está marcado por valores capitalistas, não há o que fazer.

\section{Participação social na definição da agenda de pesquisa em Ciência-Tecnologia}

A presente categoria resultou do diálogo de 40 núcleos de sentido com os referenciais anteriormente explicitados. Nessa, é analisada e/ou defendida a participação social no direcionamento dado ao desenvolvimento da CT, na agenda de pesquisa. Se, na categoria sobre determinismo tecnológico, problematizamos uma simples determinação da CT sobre a sociedade, na presente, não comparece o outro extremo: uma mera determinação social da CT. É algo mais complexo. Não se parte do zero. Já existe um aparato científico-tecnológico colocado que não pode ser ignorado e que efetivamente exerce influências sobre a sociedade.

Predomina, no conjunto dos núcleos de sentido analisados, a compreensão de uma sociedade no sentido genérico, sendo, na maioria das vezes, ignorada a existência de classes sociais distintas, a existência de uma diversidade cultural. Nesse sentido, "Este campo, de forma geral, se trata de entender os aspectos sociais do fenômeno científico-tecnológico, tanto no que diz respeito a seus condicionadores sociais quanto as suas consequências sociais e ambientais" (SOUSA et al., 2005, p. 3, grifo nosso).

Evidenciando que a discussão sobre valores e a necessidade da participação da sociedade comparece em práticas educativas analisadas, temos que,

[...] as atividades realizadas ampliaram a percepção dos alunos sobre o fato de que a sociedade deve influenciar os rumos da pesquisa e desenvolvimento científico e tecnológico, podendo orientar e sinalizar caminhos mais adequados para os mesmos, considerando não apenas suas necessidades imediatas, mas também implicações e impactos socioambientais relacionados (ARAÚJO; FORMENTON, 2012, p. 46, grifos nossos). 
Essa fala indica que, além de uma concepção genérica de sociedade, a partir do desenvolvimento da prática educativa os estudantes passaram a ter mais clareza em relação à influência que a sociedade necessita exercer nos rumos da pesquisa, no desenvolvimento da CT. A partir disso, há a possibilidade de diálogo que pode indicar a definição de possíveis caminhos para uma formação que entenda as relações de poder envolvidas nesses caminhos para CT. Há a defesa de participação pública, de uma participação cidadã na avaliação e na construção de agendas de pesquisa em CT, na definição dos problemas a serem pesquisados.

Com relação à participação social na discussão de PCT, há sinalizações animadoras. Por exemplo, "[...] o campo das políticas para facilitar a participação pública nas questões C\&T” (SANTOS; FERRARI; ALMEIDA, 2011, p. 2), “[...] nas Políticas Públicas - defendendo a regulamentação social da ciência e da tecnologia" (SILVA; PESSANHA; BOUHID, 2011, p. 2, grifo do autor) e "[...] isso se dá desde o nível da informação, até um nível mais crítico de compreensão e discussão de políticas públicas de Ciência e Tecnologia” (PORTO; TEIXEIRA, 2013, p. 5, grifo nosso).

Nessa categoria também está implícita a superação do determinismo tecnológico. Se há a defesa da participação social no direcionamento dado ao desenvolvimento da CT, está presente a compreensão, mesmo não explicitada, de que a CT não cai do céu pronta, mas recebe o condicionamento da sociedade ou de setores dessa (compreensão minoritária).

\section{Encaminhamentos promissores}

Não basta a consciência de que a agenda de pesquisa é condicionada por valores presentes na sociedade. Isso é importante e revela aspectos promissores nas práticas educativas analisadas. Revela avanços sobre a compreensão da não neutralidade da CT. Também é insuficiente - aspecto que aparece com menos intensidade na pesquisa - ter uma compreensão crítica sobre o fato de que a atual agenda está contaminada por valores particulares, capturada por interesses das transnacionais. Somente isso pode gerar passividade, conformismo.

Entendemos que é necessário avançar nos processos educativos, havendo sinais, em algumas práticas analisadas, que apontam para a compreensão de que, se buscamos uma efetiva transformação, precisamos, no mínimo, do que Dagnino (2010) chamou de AST, na qual se busca um reprojetamento da tecnociência a partir de outros valores.

Há um conjunto de núcleos de sentido, dez (10), ainda bastante frágeis, que dão consistência à presente categoria, sinalizando para o defendido no parágrafo anterior, alguns dos quais já mencionados,

[...] que as atividades realizadas ampliaram a percepção dos alunos sobre o fato de que a sociedade deve influenciar nos rumos da pesquisa e desenvolvimento científico e tecnológico, podendo orientar e sinalizar caminhos mais adequados para os mesmos, considerando não apenas suas necessidades imediatas, mas também implicações e impactos socioambientais relacionados (ARAÚJO; FORMENTON, 2012, p. 46, grifo nosso).

Os alunos puderam refletir sobre: a Ciência e os cientistas; sobre a Tecnologia e sua relação com o estilo de vida; sobre os fatores socioeconômicos a 
orientar a própria evolução da Ciência-Tecnologia; como a lógica do mercado capitalista define padrões de consumo; a importância da participação individual e social na busca pelos seus direitos; a necessidade de fazer opções responsáveis e conscientes (PORTO; TEIXEIRA, 2013, p. 8).

Como, onde e por quem é decidido que tipo ou que capacidade deve ter uma usina hidrelétrica? Onde deve ser construída? Quando as comunidades são convidadas a discutir? Ou devemos todos acreditar e concordar que uma usina como a de Itaipú é o melhor modelo? (MION; ANGOTTI; BASTOS, 1999, p. 5, grifo nosso).

Comparecem, nessa categoria, sinalizações da necessidade de engajamento na busca de alternativas, de novos caminhos para o desenvolvimento da CT. Caminhos que sinalizem alternativas para os dilemas que estamos enfrentando, por exemplo, no campo socioambiental. Comparece aquilo que Freire (2005) denominou de inédito viável ${ }^{5}$. Ou seja, entendemos que aprofundar a busca de alternativas, com contribuições de processos educativos, requer assumir um novo objetivo um tanto estranho e inédito nesse contexto: potencializar para a participação social em processos decisórios envolvendo a formulação de agendas de pesquisa, de PCT.

Tem predominado, na educação, particularmente na chamada educação ambiental, uma total separação entre a agenda educacional e a agenda de pesquisa (desenvolvimento científico-tecnológico). São dois mundos que não conversam. Enquanto que a agenda de pesquisa está capturada pela lógica da obsolescência programada, do consumo exacerbado, convidando-nos para um consumo ilimitado, a agenda educacional, ignorando essa dinâmica, em linhas gerais, continua restrita à reciclagem de lixo resultante daquela agenda de pesquisa. Nessa categoria, mesmo com sinalizações frágeis, comparecem sinais de diálogo entre esses dois campos.

\section{Participação social limitada às implicações/impactos da Ciência-Tecnologia na Sociedade}

Do total de núcleos de sentido identificados, chama a atenção um conjunto significativo (126 núcleos) que dialoga com o instrumentalismo. Concepção em que a discussão sobre valores está praticamente ausente. Ignora o processo de constituição da agenda de pesquisa, dos rumos dados ao desenvolvimento científico-tecnológico. Nessa concepção de participação, cabe à sociedade tirar o melhor proveito possível depois das CT concebidas e elaboradas (DAGNINO, 2010, 2011; FEENBERG, 2010).

Rosa (2014) realizou investigação, com corpus de análise distinto, chegando a resultados semelhantes. A autora afirma que, nos trabalhos analisados, quando a postulação de participação comparece, predominam avaliações sobre impactos do produto científico-tecnológico na sociedade, após sua produção. Segundo a autora, predomina uma defesa de participação que se limita ao que denomina de pós-produção. Depois de CT prontas, cabe à sociedade

\footnotetext{
${ }^{5}$ Para o autor, o inédito viável consiste de possibilidades ainda não percebidas, ainda não vivenciadas.
} 
participar, decidir quanto aos melhores usos para a CT. Assim, se há problemas sociais relacionados à CT, é porque a sociedade está dando um mau uso para ela.

Dos artigos que analisamos, há manifestações que expressam, com bastante eloquência, esse instrumentalismo. Reproduzimos alguns excertos representativos dessa concepção, a qual restringe a análise ao bom / mau uso, aos impactos da CT na sociedade: “[...] prejuízos foram causados pelo mau uso desses recursos pelas pessoas" (ALVES; CARVALHO, 2005, p. 6); "[...] identificar suas implicações sociais, econômicas, ambientais e culturais" (CARLETTO; PINHEIRO, 2005, p. 4); “[...] objetivávamos aproximar os alunos a múltiplas perspectivas sobre as implicações da ciência e da tecnologia pela via oferecida por um 'caso' de dano socioambiental” (ALVES; CARVALHO, 2005, p. 3, grifo do autor); “[...] é utilizada visando interesses de minorias, normalmente na perspectiva do lucro" (ALVES; CARVALHO, 2005, p. 6); “[...] refletir sobre as implicações tecnológicas, sociais, éticas e culturais nas aulas [...]" (MEZALIRA; ARAÚJO, 2007, p. 2); “[...] apesar dos benefícios que proporcionam, os impactos do desenvolvimento técnico-científico têm acarretado problemas de várias ordens, como: exclusão social, crise ambiental, crise de valores éticos, entre outros" (CARLETTO; PINHEIRO, 2005, p. 1-2).

O conteúdo dessa categoria representa desafio considerável quando se busca um nível de participação social que vá além de avaliar impactos da CT na sociedade. Discursos e práticas como avaliar impactos da CT na sociedade, trabalhar implicações sociais da CT e avaliar benefícios e malefícios do desenvolvimento da CT, transformados em senso comum, tornaram-se uma linguagem usual, comum no campo CTS. Suspeitamos que, algumas vezes, esse discurso, assumido coletivamente, omite, ofusca ações interessantes que ocorrem no âmbito de práticas educativas CTS.

\section{Sinalizações}

Com a realização da pesquisa, identificamos alguns caminhos promissores. Identificamos práticas efetivadas que sinalizam categoria freireana, o inédito viável. Isto é, a possibilidade e a necessidade de uma participação social ampliada na constituição de outras agendas de pesquisa, a partir de outros valores. Mesmo que de forma pontual, inicial, comparecem práticas sinalizadoras de potencial para, mediante processos educativos, contribuir para uma participação social ampliada em processos decisórios. Da mesma forma, entendemos que a socialização das reflexões sobre fragilidades, limitações em práticas efetivadas, considerando os referenciais que assumimos, poderá sinalizar caminhos mais consistentes e potencializadores da almejada participação. Acima de tudo, a socialização das reflexões efetivadas poderá sinalizar a necessidade de inserir novo objetivo na Educação em Ciências: a busca de uma participação social na definição de agendas de pesquisa, de PCT marcadas por demandas de segmentos sociais até então excluídos.

Quanto ao determinismo científico-tecnológico, Auler (2002) entende que, para potencializar uma maior participação social em processos decisórios, seria fundamental sua problematização, considerando que esse era entendido como gerador de passividade, de um efeito 
paralisante, uma situação-limite ${ }^{6}$ (categoria freireana). Encontramos indicativos de que essa compreensão, embora ainda minoritária no conjunto, está sendo superada.

Entendemos, a partir das análises realizadas nas cinco categorias, que a discussão sobre a presença de valores, de interesses, na definição da agenda de pesquisa, está chegando à escola, em práticas educativas do campo CTS, o que passa por uma compreensão mais crítica sobre o determinismo científico-tecnológico. Há uma razoável constatação sobre a presença de valores, de interesses, de características da sociedade na agenda de pesquisa em CT. Porém, são poucas as ações educativas que sinalizam a possibilidade e a necessidade de uma participação coletiva na definição de novas agendas de pesquisa, sustentadas por outros valores, além dos hegemônicos, que representem as necessidades da maioria da população brasileira.

Nossa pesquisa esteve motivada no que denominamos de busca de uma cultura de participação social. Uma concepção ampliada de participação. Essa cultura de participação materializa-se no diálogo, na interação com movimentos sociais externos ao espaço escolar. Desse modo, destacamos como desafio o horizonte de uma profunda reorganização espaço-temporal da escola, uma profunda modificação no campo curricular. Se houve, historicamente, um esforço para trazer o referencial freireano para o espaço da educação formal (DELIZOICOV, 2008), hoje, possivelmente, haja a necessidade de superar uma assepsia a que esse foi submetido. Entendemos como essencial um maior diálogo entre escola e comunidade (movimentos sociais, processos produtivos...), se o objetivo for efetivamente a busca dessa cultura ampliada de participação.

Como sinalização central da pesquisa, situamos o desafio para processos educativos: inserir, como objetivo assumido explicitamente, a potencialização para uma efetiva participação social em processos de definição de agendas de pesquisa, de políticas públicas para a CT. Há um razoável consenso, entre movimentos sociais que buscam a construção de uma sociedade mais justa, da necessidade de participação social na elaboração de políticas públicas para a educação, para a saúde, moradia... Contudo, ainda parece estranho defender a participação social na elaboração de PCT. Entendemos que isso está relacionado ao fato de não haver clareza sobre a não neutralidade da CT, principalmente sobre a presença de valores na definição da agenda de pesquisa. Ausência de clareza inclusive presente entre movimentos sociais, academia e processos educacionais que buscam uma sociedade mais justa.

No contexto da pesquisa, buscamos aprofundamento conceitual sobre a presença de valores no direcionamento dado ao processo científico-tecnológico. Apoiados em Lacey (2008, 2010), Dagnino (2008a, 2008b, 2010, 2011) e o PLACTS, ampliamos a compreensão sobre a não neutralidade da CT. Como síntese da compreensão alcançada, destacamos que interesses e intencionalidades presentes, incorporados no produto científico-tecnológico, têm origem na agenda de pesquisa. Ou seja, as intencionalidades, os valores presentes na definição dessa agenda são transferidos para o produto científico-tecnológico. Em nossa análise, uma compreensão parcial sobre esse processo, sobre a não neutralidade da CT, está relacionada a

\footnotetext{
${ }^{6}$ Situação-limite consiste de situação que limita o sujeito na possibilidade de ir além, de perceber outras possibilidades. Mas Freire (2005) também destaca que essas situações não devem ser tomadas como se fossem barreiras insuperáveis, além das quais nada existindo.
} 
uma lacuna no processo educacional, lacuna que faz com que seja ignorada que a gênese da não neutralidade da CT está na definição da agenda de pesquisa.

Lacuna relacionada à ausência da compreensão de que os valores, interesses e intencionalidades, materializados no produto científico-tecnológico, conferem-lhe determinadas características, o que limita, restringe o uso desses produtos. Em outros termos, há limites, por exemplo, no uso dos produtos científico-tecnológicos (meios de produção/forças produtivas), gerados e marcados por valores do modelo capitalista, para a constituição de modelos socioeconômicos distintos. Nas palavras de Varsavsky (1976, p. 14), "Nem todo estilo científico será compatível com determinado estilo de sociedade".

Entendemos que uma educação que se pretenda crítica e transformadora da sociedade não pode continuar refém do discurso do "bom/mau" uso, transformado em senso comum, um senso comum sustentado num discurso que somente se mantém se forem ignorados os valores internalizados nos produtos científico-tecnológicos, sendo os mesmos concebidos como meios, como instrumentos neutros que podem ser colocados a serviço de qualquer forma de organização social. Não podemos mais, numa perspectiva educacional crítica e transformadora, continuar silenciando, sem sinalizar novos horizontes, sobre valores assimilados e omitidos no processo científico-tecnológico atual.

Entendíamos, inicialmente, ser fundamental, para a constituição de uma cultura de participação social, uma compreensão ampliada sobre a não neutralidade, sobre a presença de valores. Hoje, constatamos que isso pode ser insuficiente. Pode, ao contrário, ser concebido como uma situação-limite: não há o que fazer, está tudo marcado por valores capitalistas, ser gerador de passividade. Sinalizamos a necessidade da efetivação, em processos educativos, de nova categoria: o inédito viável. Para a efetivação do mesmo, entendemos ser necessário o engajamento de coletivos que busquem aprofundar a discussão sobre quais valores priorizar, numa educação crítica e transformadora, assim como estruturar processos educativos coerentes com os mesmos. Fundamental, também, problematizar os silêncios sobre valores em mais da metade dos núcleos de sentidos identificados.

Silêncios portadores de imensos desafios para práticas educativas. Silêncios analisados na quinta categoria: Participação social limitada às implicações/impactos da CiênciaTecnologia na Sociedade. Compreensão que praticamente desconsidera a presença de valores. Em nossa análise, essa concepção limitada de participação decorre, dentre outras, de quatro dimensões inter-relacionadas: (1) uma compreensão limitada sobre não neutralidade; (2) influência do instrumentalismo (DAGNINO, 2010, 2011; FEENBERG, 2010); (3) influência da denominada tradição norte-americana no campo CTS; e, (4) concepção de participação social herdada do Hemisfério Norte.

Com essas quatro dimensões, queremos sinalizar caminhos investigativos. Na pesquisa, encontramos alguns elementos que apontam para sua pertinência. Avançamos no aprofundamento conceitual sobre a não neutralidade da CT. Encontramos marcas significativas do instrumentalismo. Por exemplo, participar do processo científico-tecnológico reduz-se a avaliar impactos da CT na sociedade, dar um bom uso para a mesma. Se há problemas, a sociedade está dando um mau uso para a CT. Da mesma forma, um dos eixos teóricos que têm predominado no campo CTS brasileiro consiste na denominada tradição norte-americana, a qual, segundo García, Cerezo e López (1996) focaliza as consequências sociais do desenvolvimento científico-tecnológico. Também, pelos referenciais (do Hemisfério Norte) que predominaram 
na gênese do campo educacional CTS brasileiro, é razoável admitir que o conceito de participação social carregue as marcas desse espaço-tempo. Conceito (também nas práticas efetivadas) em que está praticamente ausente a postulação de uma participação social na agenda de pesquisa, no direcionamento do desenvolvimento científico-tecnológico.

B. S. Santos (2007) ajuda a compreender o porquê dessa presença significativa em práticas educativas CTS no Brasil, da concepção limitada de participação da sociedade. Segundo ele, mesmo havendo terminado o colonialismo político, não acabou o colonialismo cultural ou social. Neste colonialismo, há uma tendência em priorizar as construções teóricas elaboradas no Hemisfério Norte. $\mathrm{Na}$ análise de Santos, há um silenciamento, um descrédito sobre tudo aquilo que não comparece nas elaborações teóricas do Norte. Há um silenciamento sobre nossa caminhada sobre formas alternativas de produção, sobre organizações econômicas populares, cooperativas operárias, empresas autogestionadas. No campo CTS, não analisado por Santos estão praticamente ausentes discussões, por exemplo, sobre o campo da agroecologia. É muito frágil a presença de Freire e do PLACTS. Freire até comparece, conforme Roso e Auler (2016), porém, esvaziado de elemento central: a investigação temática, a qual implicaria numa profunda mudança no campo curricular.

Talvez seja possível concluir, também, a partir desta pesquisa, que a própria consciência crítica pode ficar aprisionada em situações-limites. Limites que não visualizam horizontes para além da atual agenda de pesquisa, do atual desenvolvimento científico-tecnológico. $\mathrm{Na}$ pesquisa que concluímos, em um conjunto significativo de artigos, participantes do corpus, é marcante a constatação da presença de valores da lógica capitalista no direcionamento dado ao desenvolvimento científico-tecnológico. Essa constatação, se não problematizada e trabalhada conjuntamente com outra categoria freireana, o inédito viável (outras agendas de pesquisa, sustentadas em outros valores), pode, ao invés de transformação, gerar paralisia e passividade. Podem prevalecer compreensões do tipo: não há o que fazer, está tudo contaminado pelos valores capitalistas.

\section{Agradecimento}

Os autores agradecem o financiamento fornecido pela Coordenação de Aperfeiçoamento de Pessoal de Nível Superior (CAPES).

\section{Referências}

ABREU, T. B.; LIMA, B.; MARTINS, I, G. Trabalhando o conceito de energia em aulas de biologia no ensino médio em uma perspectiva CTS (Ciência-Tecnologia-Sociedade): uma análise discursiva. In: ENCONTRO NACIONAL DE PESQUISA EM EDUCAÇÃO EM CIÊNCIAS, 8., 2011, Campinas. Anais [...]. Rio de Janeiro: ABRAPEC, 2011. p. 1-14.

ALVES, J. A. P.; CARVALHO, W. L. P. Implicações CTSA na visão de alunos do ensino médio a partir do acesso a múltiplas perspectivas de um caso de dano ambiental. In:

ENCONTRO NACIONAL DE PESQUISA EM EDUCAÇÃO EM CIÊNCIAS, 5., 2005, Bauru. Anais [...]. Belo horizonte: ABRAPEC, 2005. p. 1-11. 
ANDRADE, E. C. P.; CARVALHO, L. M. O pro-álcool e algumas relações CTS concebidas por alunos de $6^{\text {a }}$ série do ensino fundamental. Ciência \& Educação, Bauru, v. 8, n. 2 , p. $167-185,2002$.

ARAÚJO, M. S. T.; FORMENTON, R. Fontes alternativas de energia automotiva no ensino médio profissionalizante: análise de uma proposta contextualizada de ensino de física em um curso técnico. Alexandria, Florianópolis, v. 5, n. 1, p. 33-61, 2012.

AULER, D. Enfoque ciência-tecnologia-sociedade: pressupostos para o contexto brasileiro. Ciência \& Ensino, Campinas, v. 1, n. esp., p. 1-20, 2007.

AULER, D. Interações entre ciência-tecnologia-sociedade no contexto da formação de professores de ciências. 2002. 258 f. Tese (Doutorado em Educação) - Universidade Federal de Santa Catarina, Florianópolis, 2002.

AULER, D.; DELIZOICOV, D. Investigação de temas CTS no contexto do pensamento latino-americano. Linhas Críticas, Brasília, v. 21, n. 45, p. 275-296, 2015.

BARBOSA, L. C. A.; BAZZO, W. A. O uso de documentários para o debate ciênciatecnologia-sociedade (CTS) em sala de aula. Ensaio: pesquisa em educação em ciências, Belo Horizonte, v. 15, n. 3, p. 149-161, 2013.

CARLETTO, M. R.; PINHEIRO, N. A. M. Enfoque CTS: repercussões de uma prática pedagógica transformadora. In: ENCONTRO NACIONAL DE PESQUISA EM EDUCAÇÃO EM CIÊNCIAS, 5., 2005, Bauru. Anais [...]. Belo Horizonte: ABRAPEC, 2005. p. 1-12.

DAGNINO, R. Um dilema latino-americano: ciência e tecnologia para a sociedade ou adequação sócio-técnica com o povo? In: DAGNINO, R. P. (org). Estudos sociais da ciência e tecnologia \& política de ciência e tecnologia: alternativas para uma nova América Latina. Campina Grande: EDUEPB, 2010. p. 265-292.

DAGNINO, R. Neutralidade da ciência e determinismo tecnológico: um debate sobre a tecnociência. Campinas: Unicamp, 2008b.

DAGNINO, R. Por que a educação em ciência, tecnologia e sociedade vem andando devagar? In: SANTOS, W. L. P.; AULER, D. (org.). CTS e educação científica: desafios, tendências e resultados de pesquisas. Brasília: Editora Universidade de Brasília, 2011. p. 99-134.

DAGNINO, R. As trajetórias dos estudos sobre ciência, tecnologia e sociedade. Alexandria, Florianópolis, v. 1, n. 2, p. 3-36, 2008a.

DELIZOICOV, D. La educación en ciencias y la perspectiva de Paulo Freire. Alexandria, Florianópolis, v.1, n. 2, p. 37-62, jul. 2008.

DELIZOICOV, D.; AULER, D. Ciência, tecnologia e formação social do espaço: questões sobre a não-neutralidade. Alexandria, Florianópolis, v. 4, n. 2, p. 247-273, 2011. 
FEENBERG, A. O que é a filosofia da tecnologia? In: NEDER, R. T. (org). Andrew Feenberg: racionalização democrática, poder e tecnologia. Brasília: Observatório do Movimento pela Tecnologia Social na América Latina, 2010. p. 49-65.

FIRME, R. N.; AMARAL, E. M. R. Analisando a implementação de uma abordagem CTS em sala de aula de química. In: ENCONTRO NACIONAL DE PESQUISA EM EDUCAÇÃO EM CIÊNCIAS, 6., 2007, Florianópolis. Anais [...]. Belo Horizonte: ABRAPEC, 2007. p. 1-12.

FREIRE, P. Pedagogia da autonomia: saberes necessários a prática educativa. 6. ed. Rio de Janeiro: Paz e Terra, 1996.

FREIRE, P. Pedagogia da esperança: um reencontro com a pedagogia do oprimido. 16. ed. Rio de Janeiro: Paz e Terra, 2009.

FREIRE, P. Pedagogia do oprimido. 48. ed. Rio de Janeiro: Paz e Terra, 2005.

FREIRE, P.; FAUNDEZ, A. Por uma pedagogia da pergunta. Rio de Janeiro: Paz e Terra, 1985.

GARCÍA, M. I. G.; CEREZO, J. A. L.; LÓPEZ, J. L. L. Ciencia, tecnologia y sociedad: una introducción al estudio social de la ciencia y la tecnología. Madrid: Tecnos, 1996.

GIL, A. C. Métodos e técnicas de pesquisa social. 6. ed. São Paulo: Atlas, 2008.

HERRERA, A. O. Ciencia y política en América Latina. 8. ed. México: Siglo XXI, 1971.

HERRERA, A. O. Los determinantes sociales de la política científica en América Latina: política científica explícita y política científica implícita. Desarrollo Economico, Buenos Aires, v. 13, n. 49, p. 113-134, 1973.

LACEY, H. Valores e atividade científica 1. São Paulo: Associação Filosófica Scientiae Studia: Editora 34, 2008.

LACEY, H. Valores e atividade científica 2. São Paulo: Associação Filosófica Scientiae Studia: Editora 34, 2010.

MEZALIRA, S. M.; ARAÚJO, M. C. A genética como foco de análise quanto às possíveis relações CTS: reflexos sobre a formação de professores no ensino superior. In: ENCONTRO NACIONAL DE PESQUISA EM EDUCAÇÃO EM CIÊNCIAS, 6., 2007, Florianópolis. Anais [...]. Belo horizonte: ABRAPEC, 2007. p. 1-10.

MION, R. A.; ANGOTTI, J. A. P.; BASTOS, F. P. Educação em física: discutindo ciência, tecnologia e sociedade. In: ENCONTRO NACIONAL DE PESQUISA EM EDUCAÇÃO EM CIÊENCIAS, 2., 1999, Valinhos. Anais [...]. Porto Alegre: ABRAPEC, 1999. p. 1-15.

MIRANDA, C. T. et al. Matemática e CTS: o ensino de medidas de áreas sob o enfoque da ciência, tecnologia e sociedade em uma escola do campo. In: ENCONTRO NACIONAL DE PESQUISA EM EDUCAÇÃO EM CIÊNCIAS, 8., 2011, Campinas. Anais [...]. Rio de Janeiro: ABRAPEC, 2011. p. 1-12. 
MONTEIRO, R.; GOUVÊA, G.; SÁNCHEZ, C. A abordagem CTSA sob a perspectiva dos temas geradores em Freire para formação continuada de professores de ciências: um campo de conflitos simbólicos na região de Angra dos Reis. Ensino, Saúde e Ambiente: REMPEC, Niterói, v. 3, n. 2, p. 155-66, 2010.

MORAES, R. Uma tempestade de luz: a compreensão possibilitada pela análise textual discursiva. Ciência \& Educação, Bauru, v. 9, n. 2, p. 191-211, 2003.

MORAES, R.; GALIAZZI, M. C. Análise textual discursiva. 2. ed. Ijuí: Ed. Unijuí, 2013.

MORAES, R.; GALIAZZI, M. C. Análise textual discursiva: processo reconstrutivo de múltiplas faces. Ciência \& Educação, Bauru, v. 12, n. 1, p. 117-128, 2006. Disponível em: http://www.scielo.br/pdf/ciedu/v12n1/08.pdf. Acesso em: 1 abr. 2019.

NASCIMENTO, T. G.; LINSINGEN, I. V. Articulações entre o enfoque CTS e a pedagogia de Paulo Freire como base para o ensino de ciências. Convergencia, Toluca, v. 13, n. 42, p. 95-116, 2006.

NIEZER, T. M.; SILVEIRA, R. M. C. F.; SAUER, E. Atividades experimentais no ensino de química avaliando as propriedades físico-químicas do leite: uma abordagem CTS. In: ENCONTRO NACIONAL DE PESQUISA EM EDUCAÇÃO EM CIÊNCIAS, 8., 2011, Campinas. Anais [...]. Rio de Janeiro: ABRAPEC, 2011. p. 1-12.

PANIAGUA, S. K. A.; SILVAS, A. P. R.; MACHADO, M. A. D. Energia nuclear no ensino médio: desenvolvendo atividades didáticas com enfoque CTSA: uma possibilidade para a formação da cidadania. In: ENCONTRO NACIONAL DE PESQUISA EM EDUCAÇÃO EM CIÊNCIAS, 9., 2013, Águas de Lindóia. Anais [...]. Rio de Janeiro: ABRAPEC, 2013. p. $1-8$.

PORTO, M. L. O; TEIXEIRA, P. M. M. Uma proposta de ensino-aprendizagem de ciências para estudantes da EJA baseada no enfoque CTS. In: ENCONTRO NACIONAL DE PESQUISA EM EDUCAÇÃO EM CIÊNCIAS, 9., 2013, Águas de Lindóia. Anais [...]. Rio de Janeiro: ABRAPEC, 2013. p. 1-8.

ROSA, S. E. Não neutralidade da ciência-tecnologia: problematizando silenciamentos em práticas educativas relacionadas a CTS. 2014. 123 f. Dissertação (Mestrado em Educação) Universidade Federal de Santa Maria, Santa Maria, 2014.

ROSA, S. E.; ROSO, C. C.; SANTOS, R. A abordagem temática na perspectiva da aproximação Freire-CTS: limites e possibilidades de engajamento de professores em formação inicial. In: SEMINÁRIO INTERNACIONAL DE EDUCAÇÃO EM CIÊNCIAS, 2., 2012, Rio Grande, RS. Anais [...]. Rio Grande: FURG, 2012.

ROSO, C. C.; AULER, D. A participação na construção do currículo: práticas educativas vinculadas ao movimento CTS. Ciência \& Educação, Bauru, v. 22, n. 2, p. 371-389, 2016.

ROSO, C. C.; DALMOLIN, A. M. T.; AULER, D. Práticas educativas balizadas por Freire e CTS. In: ENCONTRO NACIONAL DE PESQUISA EM EDUCAÇÃO EM CIÊNCIAS, 8., 2011, Campinas. Anais [...]. Rio de Janeiro: ABRAPEC, 2011.

SÁBATO, J. A ; MACKENZIE, M. La producción de tecnología: autónoma o transnacional. Ciudad de México: Nueva Imagen, 1982. 
SANTOS; A. P.; FERRARI, P. C.; ALMEIDA, N. G. Educação problematizadora no ensino de computação quântica: um caminho para a alfabetização científica e tecnológica. In:

ENCONTRO NACIONAL DE PESQUISA EM EDUCAÇÃO EM CIÊNCIAS, 8., 2011, Campinas. Anais [...]. Rio de Janeiro: ABRAPEC, 2011. p. 1-9.

SANTOS, B. S. Renovar a teoria crítica e reinventar a emancipação social. São Paulo: Boitempo, 2007.

SANTOS, R. A. Busca de uma participação social para além da avaliação de impactos da ciência-tecnologia na sociedade: sinalizações de práticas educativas CTS. 2016. 203 f. Tese (Doutorado em Educação) - Universidade Federal de Santa Maria, Santa Maria, 2016.

SANTOS, R. A. A não neutralidade na perspectiva educacional ciência-tecnologiasociedade. 2012. 100 f. Dissertação (Mestrado em Educação) - Universidade Federal de Santa Maria, Santa Maria, 2012.

SANTOS, R. A. et al. Enfoque CTS e Paulo Freire: referenciais para repensar a educação em ciências. In: SEMINÁRIO IBERO-AMERICANO CIÊNCIA-TECNOLOGIASOCIEDADE NO ENSINO DAS CIÊNCIAS, 2., 2010, Brasília. Anais [...]. Brasília: UnB, 2010. p. 1-8.

SANTOS, W. L. P. Educação científica humanística em uma perspectiva freireana: resgatando a função do ensino de CTS. Alexandria, Florianópolis, v. 1, n. 1, p. 109-131, 2008.

SILVA, F. L.; PESSANHA, P. R.; BOUHID, R. Abordagem do tema controverso radioatividade / energia nuclear em sala de aula no ensino médio: um estudo de caso. In: ENCONTRO NACIONAL DE PESQUISA EM EDUCAÇÃO EM CIÊNCIAS, 8., 2011, Campinas. Anais [...] Rio de Janeiro: ABRAPEC, 2011. p. 1-12.

SOUSA, D. R. et al. Poluição sonora na física do ensino médio: construindo uma proposta. In: ENCONTRO NACIONAL DE PESQUISA EM EDUCAÇÃO EM CIÊNCIAS, 5., 2005, Bauru. Anais [...]. Belo horizonte: ABRAPEC, 2005. p. 1-13.

SOUSA, R. G.; ALENCAR, J. R. S. Avaliando uma proposta de ensino através de temas sociais e prática CTS: o motor à combustão. In: ENCONTRO NACIONAL DE PESQUISA EM EDUCAÇÃO EM CIÊNCIAS, 6., 2007, Florianópolis. Anais [...]. Belo Horizonte: ABRAPEC, 2007. p. 1-12.

STRIEDER, R. B. Abordagem CTS na educação científica no Brasil: sentidos e perspectivas. 2012. 283 f. Tese (Doutorado em Ensino de Ciências) - Universidade de São Paulo, São Paulo, 2012.

VARSAVSKY, O. Ciencia, política y cientificismo. Buenos Aires: Centro Editor de América Latina, 1969.

VARSAVSKY, O. Por uma política científica nacional. Rio de Janeiro: Paz e Terra, 1976.

Artigo recebido em 14/02/2018. Aceito em 17/11/2018.

Contato: Universidade Federal da Fronteira Sul, Rua Jacob Reinaldo Haupenthal, 1580, Cerro Largo, RS, 97900-000, Brasil. 
